Sergio Morera-Julca, Abel Mejia-Marcacuzco, Jean Loup Guyot; Carlos Gálvez, Francisco Salinas, Manuel Collas, and Eusebio Ingol-Blanco, Uncertainty in Suspended Sediment Load Estimates for Mountain Rivers. Case of Study of Central Andes in Peru, World Environmental \& Water Resources Congress 2013, EWRI-ASCE, CINCINNATI, OHIO, May 19-23, 2013

\title{
Uncertainty in Suspended Sediment Load Estimates for Mountain Rivers. Case of Study of Central Andes in Peru
}

\author{
S. B. Morera ${ }^{1}$, Abel Mejia-Marcacuzco ${ }^{1}$, Jean Loup Guyot ${ }^{2}$; Carlos Gálvez $^{3}$, Francisco Salinas ${ }^{4}$, \\ Manuel Collas ${ }^{5}$, and Eusebio Ingol-Blanco ${ }^{6}$
}

${ }^{1}$ Water Resources Program, Universidad Nacional Agraria La Molina, Lima, Peru; PH (511) 6147800; email: sergiobaymorera@gmail.com, jabel@lamolina.edu.pe.

${ }^{2}$ Institut de Recherche pour le Développement, Peru.

${ }^{3}$ Proyecto especial Chavimochic, Trujillo, Peru.

${ }^{4}$ Proyecto especial Zaña-Jequetepeque, Lambayeque, Peru.

${ }^{5}$ Proyecto especial Tacna, Tacna, Peru

${ }^{6}$ Universidad San Ignacio de Loyola, Lima, Peru; PH (511) 317-1000, annex. 3262; email: eingol@usil.edu.pe.

\section{Abstract}

This study evaluates the uncertainty in the estimation of annual and monthly sediment flows in four mountain basins of the Pacific Ocean in Peru. For this end, samples at different time scales (hourly, daily, and monthly) were recorded. The database was broken down into a numerical base to simulate several sampling frequencies. From these timing frequencies, the annual and monthly flow was computed. Likewise, we compare the observed and simulated data, calculating the degree of uncertainty using statistical tests. The results for the 25 and 75 percentiles show that there is a high temporal variability in these Andean watersheds, whose strategy of measurement of solid flows can vary from 6 to 12 days underestimating 20\% annually. While for estimating suspended sediment yield (SY) to a monthly time step in the rainy season (December to May), a sampling frequency between 1-5 days which would lead to a maximum error of $\pm 40 \%$ is needed. However, for the dry season (June to September), the sampling can be done one time per month for an error of $\pm 45 \%$ which is less than $2 \%$ in an annual balance. Finally, the results show that the sampling frequency values mentioned above should be reduced to half, for exceptional events (rainy season) where the annual error estimate is around $300 \%$.

Key words: Uncertainty, Suspended Sediment Load, Solid Flow, Mountain Rivers, Peru.

\section{Introduction}

Uncertainty is an inherent characteristic of water resources systems (e.g.; Raje \& Mujumdar, 2010). In a general context, the existence of the uncertainty appears in the whole monitoring process, data processing and management; these include: the bias of the estimated flows during measurement (Cerdan et al., 2010), laboratory analysis (e.g.; Harmel et al., 2006), sampling strategy (Meybeck et al., 1992) and the calculation procedures method (Phillips et al., 1999); the latter is important in the period and algorithm used (eg.; Duvert et al., 2011). From the above, Birgand et al., (2010) mentions that during the evaluation of the sediment load (SSL), the uncertainty generally has two major sources: one is the sampling frequency and the other one is the method of calculation.

In fact, Morera et al., (2011) estimated the SY in the watershed under study from hourly records; they determined the resulting accuracy are given by the methods of calculation of Colby, (1956) and Walling, (1977); however, understanding sediment dynamics goes through the quantification of uncertainties in the liquid flow and suspended concentration (SCC), and its becomes even more complex without a proper strategy sampling with low temporal frequency (annual, bimonthly, monthly, weekly, etc.). One main characteristic of the study area, is the short- 